\title{
O que é uma ânfora?
}

\section{What's an amphora?}

Caio Gagliardi

Universidade de São Paulo (USP), São Paulo, São Paulo / Brasil caiogagliardi@gmail.com

Resumo: Este ensaio propõe uma análise do texto "Arte poética I", de Sophia Andresen, cuja imagem fundamental, da "ânfora", é tomada como elemento-chave para a compreensão de sua visão poética. Além da associação com outros autores, principalmente Hiromi Kawakami e Clarice Lispector, a interpretação desse objeto simbólico vale-se diretamente dos ensaios $O$ respeito ou o olhar atento (2006), de Josep Esquirol, e "A obra de arte na era de sua reprodutibilidade técnica" (1936), de Walter Benjamin.

Palavras-chave: Sophia Andresen, arte poética, Walter Benjamin, aura.

Abstract: This essay proposes an analysis of the text "Art of Poetry I" by Sophia Andresen, whose fundamental image of the "amphora" is taken as a key element for the understanding of her poetic vision. In addition to the association with other authors, especially Hiromi Kawakami and Clarice Lispector, the interpretation of this symbolic object is directly based on the essay Respect or the watchful eye (2006), by Josep Esquirol, and Walter Benjamin's "The Work of Art in the Era of Its Technical Reproducibility" (1936).

Keywords: Sophia Andresen, ars poetica, Walter Benjamin, aura.

Data de submissão: 17 de agosto de 2018

Data de aprovação: 8 de janeiro de 2019 
1.

"A literatura é a maneira mais agradável de ignorar a vida." (PESSOA, 2014, p. 114). Ou ainda: "A literatura, como toda a arte, é uma confissão de que a vida não basta." (PESSOA, 1966, p. 285). Essas frases célebres compõem a ideia de modernidade na literatura portuguesa por serem típicas da poética de seu mais influente autor. No entanto, nada mais distante de Sophia Andresen do que essas concepções, e se são aqui tomadas como pontos de partida é justamente com a intenção de iluminar pelo contraste o sentido de novidade dessa poética tão particular. ${ }^{1}$

Em um de seus textos metalinguísticos mais importantes, "Poesia e realidade" (1960), Sophia defende que a poesia advém, não da tão pessoana vontade de ignorar ou daquele seu característico sentimento de insuficiência, mas de uma necessidade de realidade, de uma ânsia de fusão com as coisas. Fugindo à fórmula horaciana, que entrevê o poético como fonte de conhecimento ou deleite, para a autora a poesia é, mais propriamente, uma forma de encontro com o real:

Se o poeta procura tanto a solidão, não é só para fugir ao rumor e à agitação, mas também para ver as coisas quando elas estão sozinhas. A emoção que sentimos ao entrar numa casa deserta ou num jardim abandonado, é a emoção de vermos como as coisas sem nós existem, na sua própria realidade, em si. É com esse em si que o poeta quer entrar em relação. (ANDRESEN, 1960, p. 53)

A autora concebe a palavra como dotada do poder encantatório de tornar a experiência mais visível, mais real. Note-se que Pessoa afirmou algo que pode se confundir com isso: "Toda a literatura consiste num esforço para tornar a vida real" (PESSOA, 2014, p. 115). Mas não confundamos. Pessoa afirma isso em termos de substituição - concebe a vida como vida literária. Já para Sophia, em suas próprias palavras, "Não podendo atingir a união absoluta com a Realidade, o poeta faz o poema onde o seu ser e a Realidade estão indissoluvelmente unidos." (ANDRESEN, 1960, p. 54). Nesse sentido, a palavra não nomeia simplesmente "o que" se vê ou "porque" se vê. Ela nomeia "para que" se veja. É exemplar dessa força individualizadora da palavra o conhecido

\footnotetext{
${ }^{1}$ Não desconsidero com esse comentário os ricos paralelos já traçados entre ambos os autores, mas procuro focar sua diferença que, a despeito daqueles, sempre me pareceu fundamental. Entre outros estudos, cf. Hörster (2017). E também Martinho (1982).
} 
poema "Lisboa" (de Navegações, 1983), cidade a qual o eu lírico se refere nos seguintes termos: "Vejo-a melhor porque digo / Tudo se mostra melhor porque digo / Tudo mostra melhor o seu estar e a sua carência/ Porque digo/ (...) / Digo o nome da cidade / Digo para ver." (ANDRESEN, 1996, p. 247). A poesia de Sophia é permeada de um fascínio pelo real natural e o seu "interior", conforme ela mesma afirma, "é uma atenção voltada para fora" (aliás, de modo só superficialmente análogo a Caeiro, porque sem drama ou ironia). Complementarmente, no mesmo "Poema", lê-se: "De tudo quanto vejo me acrescento" (ANDRESEN, 2004, p. 186). Há suficientes recorrências dessa helênica atenção circundante em sua poesia para que se possa referi-la como uma poética do olhar. Para ficarmos em apenas mais um exemplo, no significativo poema "Minotauro", de Dual (1972), encontra-se: "Porque pertenço à raça daqueles que mergulham de olhos abertos." (ANDRESEN, 1996, p. 147).

É nesse escopo que Eduardo do Prado Coelho, em "Sophia, a lírica e a lógica", define a poética andreseniana como uma "exaltação afirmativa do real" (COELHO, 1984, p.111). Complementarmente, o crítico chama a atenção para a recusa do tempo histórico em Sophia, por ser ele um tempo que divide e exila, salientando sua predileção pelo tempo mítico. Em O nome das coisas (1977) há um poema de dois versos, intitulado justamente "Exílio": "Exilamos os deuses e fomos / Exilados de nossa inteireza." (ANDRESEN, 1996, p. 220). Segundo Prado Coelho, fugindo ao exílio decorrente da opressão salazarista e colonialista em Portugal, pela degradação do projeto revolucionário do 25 de Abril e pelos conflitos da vida psíquica, contrapõe-se a imagem de um "reino individido", isto é, a aliança ideal entre as palavras e as coisas, em que o eu esvaziado volta-se para fora de si, solar, claro e bem delineado (Cf. COELHO, 1984, p. 128).

A noção de uma "exaltação afirmativa do real" retoma, a bem considerar, aquilo que Eduardo Lourenço considera, em "Para um retrato de Sophia", a "sabedoria" de sua poesia - uma sabedoria, aliás, que reside numa "simplicidade que Caeiro só em irônica visão pôde antever" (LOURENÇO, 1978, p. 3). Para Lourenço, na "topologia da aventura literária portuguesa, Sophia e Pessoa ocupam polos opostos" (LOURENÇO, 1978, p. 4). Isso porque Sophia "põe termo à longa travessia da consciência poética como consciência infeliz que começa em Antero e tem em Álvaro de Campos a sua expressão "épica" (LOURENÇO, 1978, p. 5). Segundo o ensaísta, "há poucos itinerários 
poéticos em língua portuguesa tão impregnados de positividade original." (LOURENÇO, 1978, p. 2).

\section{2.}

Impregnada de imagens concretas, o traço da poética de Sophia que se procura aqui salientar encontra uma de suas mais altas sínteses na imagem da ânfora. Em Pessoa, ainda por contraste, essa é uma imagem previsível: "Meu coração é uma ânfora que cai e que se parte...", lê-se em "Hora absurda", ou "O poeta é grato à sua esbelteza como o fora à esbelteza da ânfora, onde o vinho se contivesse" (PESSOA, 2014, p. 339), quando se refere à Khayyaam no Livro do desassossego. Ou é ainda "ânfora inútil", simplesmente. O que um vaso de cerâmica usado pelos gregos e romanos para conservar vinho, azeite, água ou cereais pode nos ensinar? Esta pergunta está subjacente à maneira como Sophia olha para a ânfora.

$\mathrm{O}$ texto fundamental a esse respeito e revelador de seu olhar poético foi escrito numa prosa eivada de lirismo, em primeira pessoa, e abre uma série numerada de I a V, intitulada "Arte poética". Se na Antiguidade e no Renascimento a arte poética apresentava natureza prescritiva, aqui ela é minimalista, individual e não tem caráter técnico, é antes direcionada à desocultação do real. Estamos diante de uma narrativa de duas páginas, quase toda descritiva. O espaço é a cidade de Lagos, no Algarve, e no auge do verão, em torno de meio-dia. Em seu caminho pela cidade, a claridade e o calor forçam a narradora a procurar a fita estreita de sombra rente ao muro por que passa. O texto é envolto em sensorialidade. Ela está à procura da loja de barros situada "numa pequena rua do outro lado da praça" - em um endereço quase secreto, um outro lado algo iniciático, "depois da taberna fresca e da oficina do ferreiro" (ANDRESEN, 2004, p. 187).

Há um tom oriental em "Arte poética I". A descrição da narradora confere tamanha atenção e respeito a objetos tão simples, cujos melhores paralelos encontramos na literatura oriental. Em $A$ valise do professor, por exemplo, romance de Hiromi Kawakami, Tsukiko é a narradora solitária que, já beirando os 40 anos, encontra por acaso seu antigo professor de japonês no ensino médio, Harutsuna, um homem tradicional e também solitário, com quem desenvolve uma relação ambígua, até certo ponto austera, mas regada a saquê. Num dia frio e de vento forte, Tsukiko vai a Kappabashi, a trabalho. Embora a narradora não nos explique, 
Kappabashi é um conhecido mercado de rua nas cercanias de Tóquio voltado a utensílios de cozinha. Encantada, ela entra na loja onde há, entre muitos utensílios, caçarolas e tigelas. Então lê-se:

Em Kappabashi há muitos atacadistas de objetos de louça e de laca. Caçarolas, panelas de ferro, pratos e tigelas, todo tipo de objetos para cozinha. Depois de concluir meu compromisso, decidi dar uma espiada nas lojas. As caçarolas de cobre de mesmo tipo e em diversos tamanhos estavam postas uma dentro das outras formando conjuntos, da maior até a menor, como as bonecas russas matrioska. Caçarolas de barro imensas adornavam a entrada das lojas. Escumadeiras e conchas de vários tamanhos estavam dispostas. Havia lojas de cutelaria. Dentro das vitrines alinhavamse lâminas e facões pontiagudos, sem seus cabos, facas para cortar legumes e outras mais finas, próprias para o corte de peixes. Havia de cortadores de unha a tesouras de cortar flores.

Encantada com o brilho das lâminas, entrei na loja, onde a um canto se empilhavam alguns raladores metálicos. "Liquidação", estava escrito em um papelão preso por um elástico aos cabos de um grupo de raladores de tamanhos variados.

(...)

Comprei um novo ralador pensando em presenteá-lo ao professor. (KAWAKAMI, 2012, p. 43-44)

Tsukiko confessa que estar ali desperta o desejo de consumir, e que contemplar a lâmina brilhante do ralador de mil ienes acende a vontade de rever o professor. Nesse ponto já estamos novamente distantes da prosa de Sophia, mas é notável a semelhança de cenário e, especialmente, o olhar atento que a personagem dirige a esses objetos do cotidiano.

A noção de olhar atento é explorada pelo filósofo espanhol Josep Esquirol de uma perspectiva ética, como um movimento da atenção cujo ponto de partida apresenta uma natureza paradoxal, uma vez que "a total facilidade de olhar contrasta com a dificuldade de olhar bem" (ESQUIROL, 2009, p. 11). O olhar insistente ou indiscreto, como o retratado em Rear Window (1954), de Hitchcock, contrasta com o movimento do respeito, que implica uma aproximação cuidadosa, capaz de guardar a devida distância. Essa justa medida com os outros e as coisas traduz-se como a sutil distância que, uma vez perdida, torna-se intromissão, invasão. Todo o romance de Kawakami é um exercício de olhar atento às coisas (o copo de saquê, o ralador, a valise do professor), 
à natureza (o chiar do grilo, o claro da lua, o veio de água) e ao corpo do professor. No decorrer dessa delicada relação entre uma ex-aluna e seu antigo mestre, preserva-se aquela formalidade que temos ao entrar na casa de um desconhecido, o cuidado com que caminhamos numa loja de cerâmica ou a distância que mantemos de um quadro num museu. Estamos muito próximos, afinal, da atenção que a narradora de Sophia confere à ânfora na loja de barros. Em seu "Poesia e realidade" lê-se justamente: "O poeta é aquele que vive com as coisas, que está atento ao Real, que sabe que as coisas existem." (ANDRESEN, 1960, p. 53).

Esse olhar talvez se deva à delicada habilidade que algumas pessoas possuem de ritualizar a vida. Após certa hora da tarde, a "hora perigosa", em que os filhos e o marido ainda não retornaram a casa e nada mais "precisa de sua força", Ana, a protagonista do conto "Amor", de Clarice Lispector, inquieta-se. Nessas horas mortas do dia afloram os anseios emudecidos pelos afazeres diários. Mas são eles, e sobretudo a maneira como os encara, os aliados de Ana. Isso porque a limpeza da casa não se limita a denunciar o lugar da mulher numa sociedade patriarcal, vitimizando-a. Nesse conto, a sutileza está em, sem apagar esse seu traço, acrescentar-lhe outro: as tarefas domésticas são encaradas pela protagonista de tal modo a se assemelharem, ali, à cerimônia do chá. Não se trata de um teste de eficiência e poupança de energia, tampouco, na leitura que o conto reclama, de uma tarefa sisifiana. Assim como a cerimônia do chá é um caminho zen, que requer conhecimento e estudo contínuo, o valor das tarefas cotidianas de Ana está no modus como ela as realiza. Esse esvaziamento de fundo estético é capaz de equilibrar, é verdade que por caminhos tortos, suas dores existenciais.

Todo o seu desejo vagamente artístico encaminhara-se há muito no sentido de tornar os dias realizados e belos; com o tempo, seu gosto pelo decorativo se desenvolvera e suplantara a íntima desordem. Parecia ter descoberto que tudo era passível de aperfeiçoamento, a cada coisa se emprestaria uma aparência harmoniosa; a vida podia ser feita pela mão do homem. (LISPECTOR, 1998, p. 20)

O texto de Sophia compartilha dessa mesma aparência harmoniosa, mesmo de uma compostura, que rituais como o shodô, a caligrafia japonesa feita com tinta nankim sobre papel de arroz, o ikebana, os arranjos florais ou via das flores, por ser também um caminho, a exemplo do caratê e do judô, e ainda o touguei, a arte em cerâmica, que 
envolve uma relação profunda com os quatro elementos da natureza, a terra, a água, o fogo e o ar, procuram ensinar.

"Arte poética I" é um quadro chiaroscuro construído em torno das sensações de calor e frescor, luz e sombra. Tal como Tsukiko, a narradora entra na loja de barros e passa a descrever as prateleiras e o chão cobertos de louças, bem como sua matéria-prima, as duas espécies de barro: "Barro que desde tempos imemoriais os homens aprenderam a modelar numa medida humana. Formas que através dos séculos vêm de mão em mão. A loja onde estou é como uma loja de Creta." (ANDRESEN, 2004, p. 187). Lembremos que Creta, centro da civilização mais antiga da Europa, tem uma história repleta de lendas transmitidas oralmente - o rei Minos, Theseus, Minotauro, Dédalus e Ícarus são alguns de seus célebres personagens. É a esta Creta lendária, a dos tempos imemoriais, portanto, e não aquela apinhada de turistas, que a autora faz referência. A loja de barros associa-se, afinal, ao princípio lendário de tudo, a uma terceira margem fora do tempo contingente. E esse princípio tem forma humana. Uma ânfora, afinal, não surge de um molde, modela-se manualmente, carrega, portanto, em sua forma e dimensões a lembrança da anatomia humana, como uma impressão digital.

O texto de Sophia é marcado pela repetição, com pequenas variações, da frase "olho para a ânfora", que exerce o papel de refrão e traz outro elemento-chave para sua compreensão: antecedido pelo substantivo "ânfora", o verbo "olhar". Em certo sentido, "Arte poética I" é uma pedagogia do olhar porque celebra um ritual de contemplação e respeito aos elementos que nos são constitutivos: "Olho as ânforas de barro pálido poisadas em minha frente no chão.” (ANDRESEN, 2004, p. 187). Nessa drummondiana lição de coisas, os objetos passam a servir aos olhos, alguns diriam ao espírito.

Neruda faz esse exercício com objetos banais. Em "Ode à cebola", o poeta chileno resgata esse legume de nossa cegueira constitutiva, ou do olhar automático que dirigimos a ele, e ao invés de destiná-lo ao corriqueiro, isto é, ao corte e às frigideiras, atribui-lhe o estatuto de obra de arte da natureza. Bastará lembrar as Odes elementares, de Neruda (1977), dedicadas à colher, à batata, ao tomate, à alcachofra, à cebola etc. ${ }^{2}$ De modo análogo, em "Lâmpada", do poeta mineiro Donizete Galvão,

\footnotetext{
${ }^{2}$ Cf. a bela crônica de Rubem Alves, intitulada "A complicada arte de ver", publicada no jornal Folha de S. Paulo, 26 out. 2004.
} 
lê-se logo de início: "De tanto ser vista, / gasta-se a beleza / das coisas que em si / guardam a perfeição." (GALVÃO, 2003, p. 48). Já os objetos de Sophia são selecionados, guardam uma simplicidade constitutiva em sua forma que não se pode chamar de banal. Acrescente-se ainda ao olhar que a narradora dirige à ânfora uma "reserva", e em sua manipulação "um jeito recolhido e meio religioso". Não será fácil encontrar um paralelo mais apropriado a esse olhar dirigido para a ânfora, que é um olhar para a própria poesia e, no fundo, para si, do que aquele que se pode traçar com o poema "O ovo de galinha", de João Cabral de Melo Neto. São dele as expressões citadas. Ali, o elemento espiritual ou sagrado, porque ligado à origem da vida, está associado à forma simples, obra de "mil inacabáveis lixas / usadas por mãos escultoras / escondidas na água, na brisa." (MELO NETO, 1994, p. 303). Mas é o olhar, ou a arte de olhar, que encaminha o sentido das coisas. Em "Oração natural", do mesmo Donizete Galvão, todos os inícios de período são marcados pela afirmação "Fique atento", por exemplo: "Fique atento / aos sulcos / de sal / de sua face". Até o desenlace: "A atenção: forma natural / de oração." (GALVÃO, 2003, p. 62). Esse aspecto religioso, tão presente no poema de João Cabral, no sentido etimológico da palavra, isto é, de religação, é um traço constitutivo da lição de coisas andreseniana.

Referindo-se à ânfora, a narradora de Sophia especula o seguinte: "Talvez a arte deste tempo em que vivo me tenha ensinado a olhá-las melhor. Talvez a arte deste tempo tenha sido uma arte de ascese que serviu para limpar o olhar." (ANDRESEN, 2004, p. 187). Já na Antiguidade, a ânfora não era apenas um objeto utilitário. Os inúmeros cacos recolhidos incansavelmente pelos arqueólogos representam, pouco a pouco, cenas de caça e do cotidiano, batalhas e rituais religiosos, fazendo as vezes de um imenso arquivo histórico disperso sob o solo em que pisamos. Não é, entretanto, como documento do passado, muito menos como vaso decorativo ou simplesmente para guardar mantimentos que a ânfora serve à narradora. Ela é aqui, fundamentalmente, objeto simbólico. Seu valor, mais precisamente, pode ser mais bem descrito por aquilo que Walter Benjamin definiu como valor de culto.

\section{3.}

Em "A obra de arte na era de sua reprodutibilidade técnica", Benjamin nos lembra que há toda uma arte feita para não ser vista, como 
certas estátuas divinas que permanecem cobertas quase o ano inteiro e certas esculturas em catedrais medievais que se situam em pontos tão altos que não se pode observar do chão a olho nu. O que dizer então do alce desenhado pelo homem paleolítico no fundo das cavernas? Esse foi um desenho feito para ser visto apenas pelos espíritos, para que a caça de fato se realizasse. Seu valor não é propriamente estético, porque não podemos pensar em exposição ou apreciação nesse caso. Ele está associado ao ritual que o presentifica, a existência em si. Quando reproduzimos essa imagem da rocha escura em milhares de páginas de livros de história da arte ou na internet, destacamos a imagem do seu aqui e agora. É por esse motivo que nenhuma cópia do Davi de Michelangelo, a exemplo da estátua exposta aos olhos dos turistas em frente à Galeria Ufizzi, em Firenze, pode rivalizar com o original. Custa tempo e dinheiro apreciar o Davi de Michelangelo porque ele é um objeto integrado ao domínio da tradição, que preserva o seu tempo e o seu espaço - nas palavras de Benjamin, ele é um testemunho histórico e uma duração material. Essa marca viva duradoura da tradição, como uma pegada ou um autógrafo (e não faz sentido tirarmos a foto de um autógrafo; seu valor está em ele ser único), é dotada de uma autoridade e desperta uma emoção histórica que desaparece diante da cópia. Quando reproduzimos esses objetos que, ao contrário dos rolos de filme, por exemplo, não foram feitos para serem reproduzidos, algo se perde - a sua autenticidade. Quando tornamos serial um objeto que surgiu para ser único, roubamos a sua aura. A nossa atual forma de percepção, estritamente relacionada que está ao valor de posse (expressão esta que poderíamos acrescentar à reflexão de Benjamin) rouba a unidade e durabilidade do objeto não serial. A nossa mania de fotografar tudo torna múltiplo aquilo que era único, próximo aquilo que era distante. A reprodução que possuímos é, no entanto, transitória e repetível, emancipada de sua existência essencial, desenraizada de sua tradição. A reprodução é, afinal, um analgésico às nossas angústias diante do objeto aurático.

Essa rápida paráfrase benjaminiana tem aqui uma função instrumental. Note-se que, em "Arte poética I", ao se referir à beleza indescritível da ânfora, a narradora a especifica: "Não falo de uma beleza estética mas sim de uma beleza poética." (ANDRESEN, 2004, p. 187). As expressões beleza estética e beleza poética poderiam ser substituídas, numa tradução benjaminiana, por valor de exposição e valor de culto, respectivamente. Não será preciso enchê-la de água para que a 
ânfora dê de beber, porque este verbo assume uma conotação espiritual no texto, assim como o olhar para a ânfora significa tanto contemplar quanto discernir: "Mas já agora ela me dá de beber. Paz e alegria, deslumbramento de estar no mundo, religação." (ANDRESEN, 2004, p. 187). Este último termo, cuja etimologia é a mesma da palavra religião, remonta às origens: a ânfora carrega consigo o princípio de tudo, o barro de onde viemos, e, por isso mesmo, conforme a narradora, "estabelece uma aliança entre mim e o sol." (ANDRESEN, 2004, p. 188).

Note-se, no entanto, que não há apenas uma ânfora na loja de barros, mas centenas delas: "Olho para a ânfora igual a todas as ânforas, a ânfora inumeravelmente repetida" (ANDRESEN, 2004, p. 188). Trata-se de um objeto repetível? Serial, como as quinquilharias vendidas na rua? Muito pelo contrário, a ânfora é um objeto "que nenhuma repetição pode aviltar porque nela existe um princípio incorruptível." (ANDRESEN, 2004, p. 188). A narradora confere densidade ao que vê, atribui valor de culto ao objeto. Numa expressão, esse princípio incorruptível não é outra coisa senão o que Benjamin definiu por aura. Os badulaques, berloques e penduricalhos que lhe são oferecidos, "não têm nada de comum nem comigo nem com o sol. Vem de um mundo onde a aliança foi quebrada." (ANDRESEN, 2004, p. 188). Note-se que a ânfora é aqui exemplo maior de um mundo concreto ao qual a autora é fiel e está atenta, com que convive e, mais ainda, através do qual busca reencontrar-se.

Museu necessário, essa poesia de terra e sol, vento e mar, compõe sua biografia e seu rosto, é sua realidade e sua forma de ligar-se ao mundo. Assim, por ser um objeto aurático, nenhuma repetição é capaz de destacar da ânfora sua união harmoniosa. Não é como as mercadorias, objetos industrializados que povoam um mundo líquido e dispersivo, ou de verdades implantadas, seja como for, um mundo que "não está religado nem ao sol nem à lua, nem a Ísis, nem a Deméter, nem aos astros, nem ao eterno. Mundo que pode ser um habitat mas não é um reino." (ANDRESEN, 2004, p. 188).

A presença dessas divindades em "Arte poética I" está longe de ser gratuita. Suas lendas são análogas e apresentam forte simbologia. $\mathrm{Na}$ mitologia do Egito Antigo, Ísis representa a fertilidade, é a deusa mãe e protetora. Através de sua magia, reuniu o corpo de seu marido e irmão, Osíris, devolvendo-lhe a vida. Seu filho é Hórus, deus dos céus, cujos olhos representam o sol e a lua. Analogamente, na mitologia da Grécia Antiga, Deméter é cultuada como deusa da agricultura, responsável pelas 
terras férteis e pela colheita. Do mesmo modo, é casada com seu irmão Zeus (que fora salvo por sua mãe, Reia, de ser engolido por Cronos, seu pai). E mãe de Perséfone, que, raptada por Hades, é destinada a passar metade do ano nas profundezas infernais, período em que as terras permanecem inférteis. Ambos os mitos, ligados à terra e ao batimento próprio da vida, apresentam o contraste entre luz e sombra presentes em "Arte poética I".

Essa concepção de mundo não corresponde, no entanto, ao mundo em que vivemos, à chamada Modernidade, que se traduz no texto de Sophia como "habitat", em oposição à noção de "reino". Por esse motivo, a poética da autora se apresenta como resistência necessária à quebra de aliança entre os homens e as coisas: "O reino agora é só aquele que cada um por si mesmo encontra e conquista, a aliança que cada um tece." (ANDRESEN, 2004, p. 188). Essa é uma poética que ritualiza a existência, que atua como forma de conferir densidade, de resgatar o peso próprio de cada coisa, e, em especial, a sua medida humana. Escrever é, para Sophia, religar, tecer essa aliança perdida entre os homens e as coisas. Daí o tom de celebração de seu texto: "Este é o reino que buscamos nas praias de mar verde, no azul suspenso da noite, na pureza da cal, na pequena pedra polida, no perfume do orégão." (ANDRESEN, 2004, p. 188). Sua poética atua como resposta ao reino dividido, "semelhante ao corpo de Orpheu dilacerado pelas fúrias". Seu tecido fino é cozido de palavra em palavra, uma unidade que se faz "de coisa em coisa":

É por isso que eu levo a ânfora de barro pálido e ela é para mim preciosa. Ponho-a sobre o muro em frente do mar. Ela é ali a nova imagem da minha aliança com as coisas. Aliança ameaçada. Reino que com paixão encontro, reúno, edifico. Reino vulnerável. Companheiro mortal da eternidade. (ANDRESEN, 2004, p. 188)

\section{Referências}

ANDRESEN, Sophia de Mello Breyner. Obra poética III. Lisboa: Editorial Caminho, 1996.

ANDRESEN, Sophia de Mello Breyner. Poemas escolhidos. Org. Vilma Arêas. São Paulo: Companhia das Letras, 2004.

ANDRESEN, Sophia de Mello Breyner. Poesia e realidade. Colóquio Revista de Artes e Letras, Lisboa, n. 8, p. 53-54, abr. 1960. 
BENJAMIN, Walter. A obra de arte na era de sua reprodutibilidade técnica. In: . Magia e técnica, arte e política. Trad. Sérgio Paulo Rouanet. Pref. Jeanne Marie Gagnebin. São Paulo: Editora Brasiliense, 2011.

COELHO, Eduardo Prado. Sophia, a lírica e a lógica. In: . A mecânica dos fluidos: literatura, cinema, teoria. Lisboa: Imprensa Nacional; Casa da Moeda, 1984.

ESQUIROL, Josep M. O respeito ou o olhar atento: uma ética para a era da ciência e da tecnologia. Trad. Cristina Antunes. Belo Horizonte: Autêntica, 2009.

GALVÃO, Donizete. Mundo mudo. São Paulo: Nankin Editorial, 2003. HÖRSTER, Maria António; SILVA, Maria de Fátima. Sophia na Grécia, evocando Fernando Pessoa. Nuntius Antiquus, [S.1.], v. 13, n. 1, p. 59-84, ago. 2017.

KAWAKAMI, Hiromi. A valise do professor. Trad. Jefferson José Teixeira. São Paulo: Estação Liberdade, 2012.

LISPECTOR, Clarice. Amor. In: . Laços de família. Rio de Janeiro: Rocco, 1998.

LOURENÇO, Eduardo. Para um retrato de Sophia. In: ANDRESEN, Sophia de Mello Breyner. Antologia. Lisboa: Moraes Editores, 1978.

MARTINHO, F. J. B. Sophia lê Pessoa. Persona, Porto, n. 7, p. 26-29, 1982.

MELO NETO, João Cabral de. O ovo de galinha. In: . Obra completa (Serial). Rio de Janeiro: Editora Nova Aguilar, 1994.

NERUDA, Pablo. Odes elementares. Luís Pignatelli. Lisboa: Publicações Dom Quixote, 1977.

PESSOA, Fernando. Erostratus. In: LIND, Georg Rudolf; COELHO, Jacinto do Prado (Ed.). Páginas de estética e de teorias literárias. Fernando Pessoa. Lisboa: Ática, 1966.

PESSOA, Fernando. Livro do desassossego. Ed. Richard Zenith. Porto: Assírio e Alvim, 2014. 